\title{
LANGUAGE INTEGRATED AND CRITICAL DIGITAL LEARNING: FACE-TO-FACE AND TELEMATIC TEACHING IN ARCHITECTURAL COMPOSITION SUBJECTS
}

\author{
V. Cristini, L. García, M. Diodato, C. Mileto, F. Vegas \\ Universitat Politécnica de Valéncia (SPAIN)
}

\begin{abstract}
For more than a decade, higher education has promoted the learning and increasingly widespread use of English and regional-local languages within universities. Specific reasons for this trend include the expansion of university access policies, the creation of the European Higher Education Area (EHEA), the globalization of the world economy and migratory movements. In this framework foreign languages, and especially English as the" lingua franca" of communication, play a special role in the international university of the 21st century. At the same time local identity and regional official languages other than Spanish are an extra incentive to add to the linguistic wealth of the teaching offer.

Within this framework, the text presents a series of points of contact between the application of a language policy in face-to-face and online teaching. This text focuses on a series of core subjects that have been taught in the area of Architectural Composition (Architectural Conservation, Architectural Composition) in Spanish, Valencian and English. Within the framework of the Educational Innovation Project "ARQUITECTURA CRÍTICA. Development of a methodology to work Critical Thinking in architecture students", several multilingual resources have been developed with academic content adapted to several languages. After a brief presentation of the history of these subjects, the text aims to underline the strategies required for multilingual programmes, both face-to-face and at a distance, with special emphasis on the linguistic and pedagogic skills of the teaching staff, as well as the students.
\end{abstract}

Keywords: EMI, virtual classroom, ICHLE, multilingualism, critical architecture.

\section{INTRODUCTION}

This text is linked to two different subjects from the Degree in Foundations of Architecture at the Higher Technical School of Architecture of the Universitat Politècnica de València (UPV). These are "Architectural Composition" and "Architectural Conservation" two compulsory subjects from 4th and 5th year respectively, within the Department of Architectural Composition [8,9]. After years teaching through Spanish, since the 2015/2016 academic year the authors have been progressively using English and Valencian as vehicular languages.

In addition, thanks to the Project for Educational Innovation and Improvement, funded by the UPV Institute of Education Sciences "ARQUITECTURA CRITICA. Development of a methodology to work Critical Thinking in architecture students" this experience has been enhanced in the academic year 2019/2020, gradually adapting to the health emergency and the subsequent implementation of online teaching, both in Valencian and English.

\section{EMI-ICLHE: NEW CHALLENGES TO MULTILINGUAL LEARNING}

For over a decade, higher education both in Spain and Europe has promoted the learning and increasingly widespread use of English and other languages within universities. The expansion of university admission policies, the creation of the European Higher Education Area (EHEA), the globalization of world economy, and migratory movements can be quoted as obvious justifications for the necessary examination of the role of foreign languages, particularly English as a lingua franca for communication, in the international university of the 21 st century $[6,7]$.

In keeping with this the document drawn up by the Spanish Ministry for Education, Culture and Sport "Estrategia para la Internacionalización de las Universidades Españolas 2015-2020"[1] recommends measures to increase the international appeal of universities such as "increasing the number of bilingual Degree and Master's programmes, taught in Spanish and English or other foreign languages" 
and "promoting learning of English to a level high enough for the entire teaching and research staff, administrative staff and academic posts."

It should also be remembered that in 2008 the European Commission established the goal of all European Union citizens having a good command of two languages other than their mother tongue, as part of the programme known as (2+1). In this new context where multilingualism is a strategic axis in the university internationalization process a series of criteria, objectives, and procedures are relevant to the promotion of a homogeneous process with the consensus of teachers guaranteeing high-quality teaching and learning [6].

We are currently experiencing a situation in European universities where the development of international profiles, and with it the desire to provide students with specific skills for working in a globalised professional sphere, have given rise to initiatives for improving the multilingual and intercultural communication skills of graduates [2]. In some cases these initiatives have had the firm support of Spanish universities including the Universitat Politècnica de València, specifically the Higher Technical School of Architecture, which has been teaching the Degree in Foundations of Architecture, in three official languages: Spanish, Valencian and English since the 2015/2016 academic year. The aim of this was to develop the full linguistic ability of students, implementing a multilingual system in the design of subjects.

\subsection{Aspects to consider in multilingual teaching}

Several aspects suggest that multilingual subjects help to boost the global profile of universities. These include the improvement of the linguistic skills of students in several languages, understood as an additional element which enriches their professional profile; an awareness of the benefits in terms of academic performance and the skills stemming from the transmission, and work with highly complex material through oral and comprehension processes in a language other than the mother tongue; and also the contribution to the professional development of the teaching staff taking part. Furthermore, it seems relevant to analyse the contribution of future graduates to the professional markets and to society at large. Employability is a factor to be taken into account prior to making any decisions on what type of studies should be offered in their multilingual form [3].

At this stage there is a crucial aspect to be examined, deciding which model of multilingual education to offer. In Europe and Spain many feel that the logical and obvious option is the use of English in English-Medium Instruction (EMI).

However, others feel that it would be more effective to implement a programme for the Integration of Content and Language in Higher Education or ICLHE, specifically for higher education. This represents a desire to transfer the benefits of this type of approach, widely described in primary and secondary education, to higher education. While EMI tends to be chosen in contexts where the development of language skills in a foreign language is not essential or even an objective to be considered, ICLHE is more commonly used when there is a more or less explicit intention to promote the improvement in the comprehensive use of languages by students [5].

\section{STRATEGIES TO PROMOTE THE CRITICAL APPROACH OF STUDENTS IN A MULTILINGUAL SETTING}

In this context it is important to mention some of the challenges faced in the implementation of multilingual subjects, many of which are general but can be highly influential in the critical approach of students. One of these, although not necessarily the most important, is the challenge stemming from the problems of use of language (fig.1). Teaching academic content through a foreign language rests on three pillars: the command of the teaching language, an efficient teaching methodology and personal attitude. Therefore, these guidelines have been followed to structure the multilingual teaching of architectural composition and conservation [4].

\subsection{Steps carried out for the transition to a multilingual system}

One of the main actions carried out has been the transition of existing teaching resources to new presentations adapted to English and Valencian. Teaching material resources in Spanish are high quality, with unpublished images, archive images, details of works ...

Therefore, the graphic content of the presentations has been preserved but high-quality texts in English or Valencian with well-known points of reference in their original version have been added 
(Weiler 2017). Visually, the teaching material provided to the student from the multilingual group is no different from the resources in Spanish, although the content is. This is not a literal translation, but an adapted one.
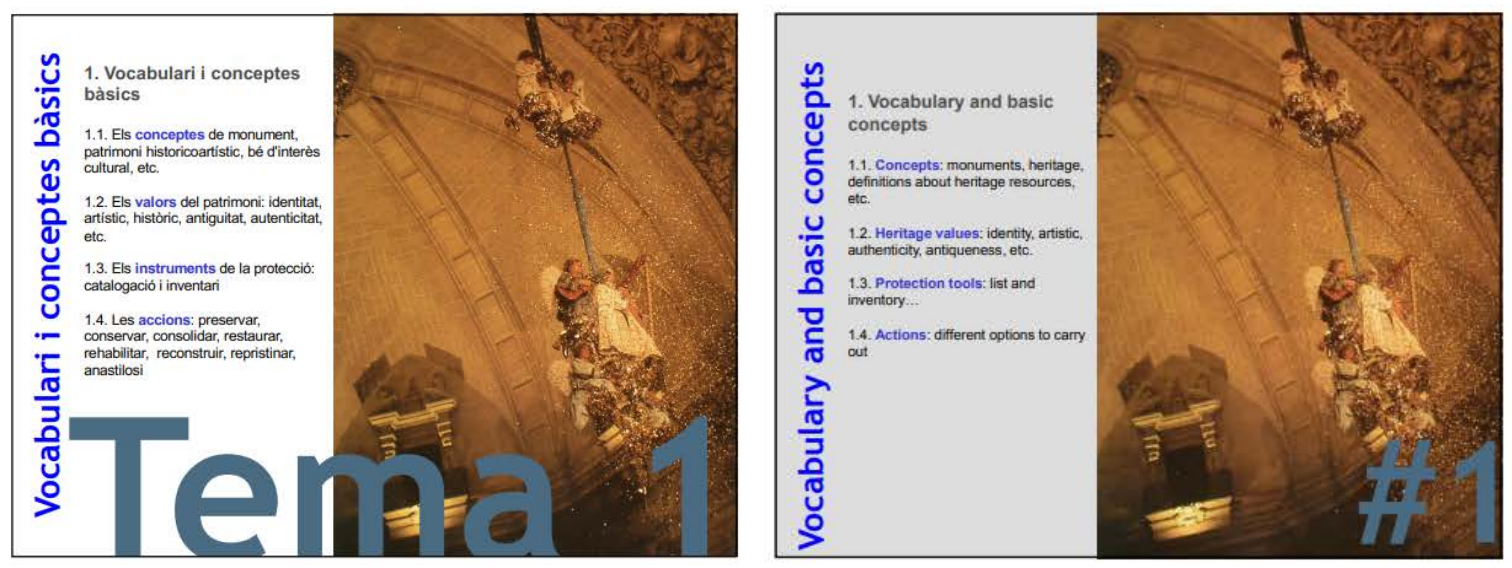

Figure 1. Definition of vocabulary as a tool for ICLHE.

Source: Mileto C.\& Cristini V. notes from the subject of Architectural Conservation (2015)

Another point developed is the selection of a bibliography in English and another in Valencian to adapt the resources complementing teaching material (Power Point presentations) previously mentioned (fig.2).

The bibliography has been compiled to provide the students with easily accessible resources (available in the archives of the UPV campus) as well as high-quality analogue points of reference, accessibility and online consultation. This is not simply a thematic bibliography for the discipline of conservation or composition, but also for technical vocabulary.

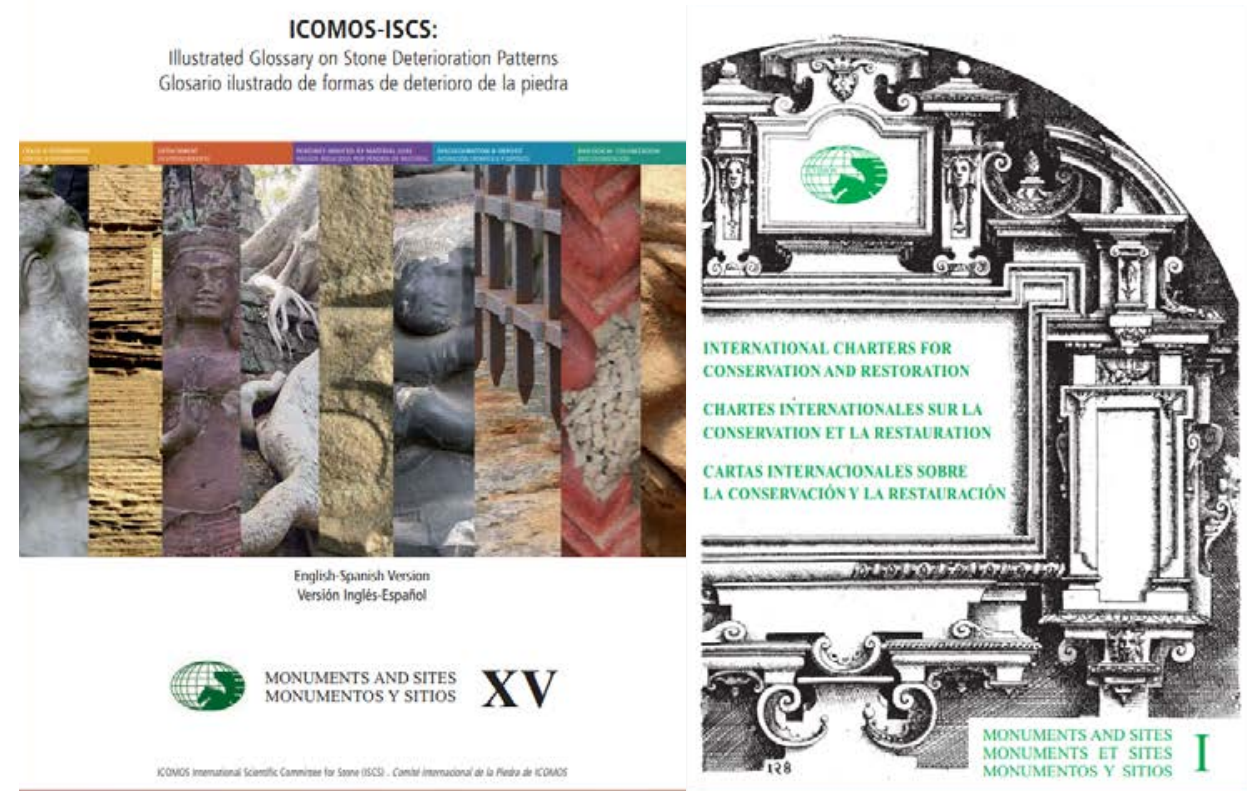

Figure 2. Selection of bibliography, subject of architectural conservation in English Source: ICOMOS

In order to improve the vocabulary and academic discourse in the classroom at the end of each class it was decided to set and highlight some key concept linked to the subjects, both in Valencian and English. To do so, at the end of each class a brief summary of some important keywords for the unit/lesson analysed is provided on the board. This selection of "Keywords" is suggested and guided by the students themselves, thus encouraging critical analysis and feedback for the teacher. 
The health emergency due to the global Covid19 pandemic has forced teachers from the subjects previously mentioned to adapt and improve certain resources which already existed and which had to be moulded to the new approach for teaching content on institutional platforms (Teams and Poliformat UPV- fig.3). To do this a series of media resources have been selected to complement multilingual teaching. This was done to help students make full use of a careful selection of original audiovisual material linked to the themes of the subjects in order to improve pronunciation, oral production, vocabulary and comprehension. These basic resources were also created with the support and selection of media by the students themselves, filtered and reviewed by the teachers.

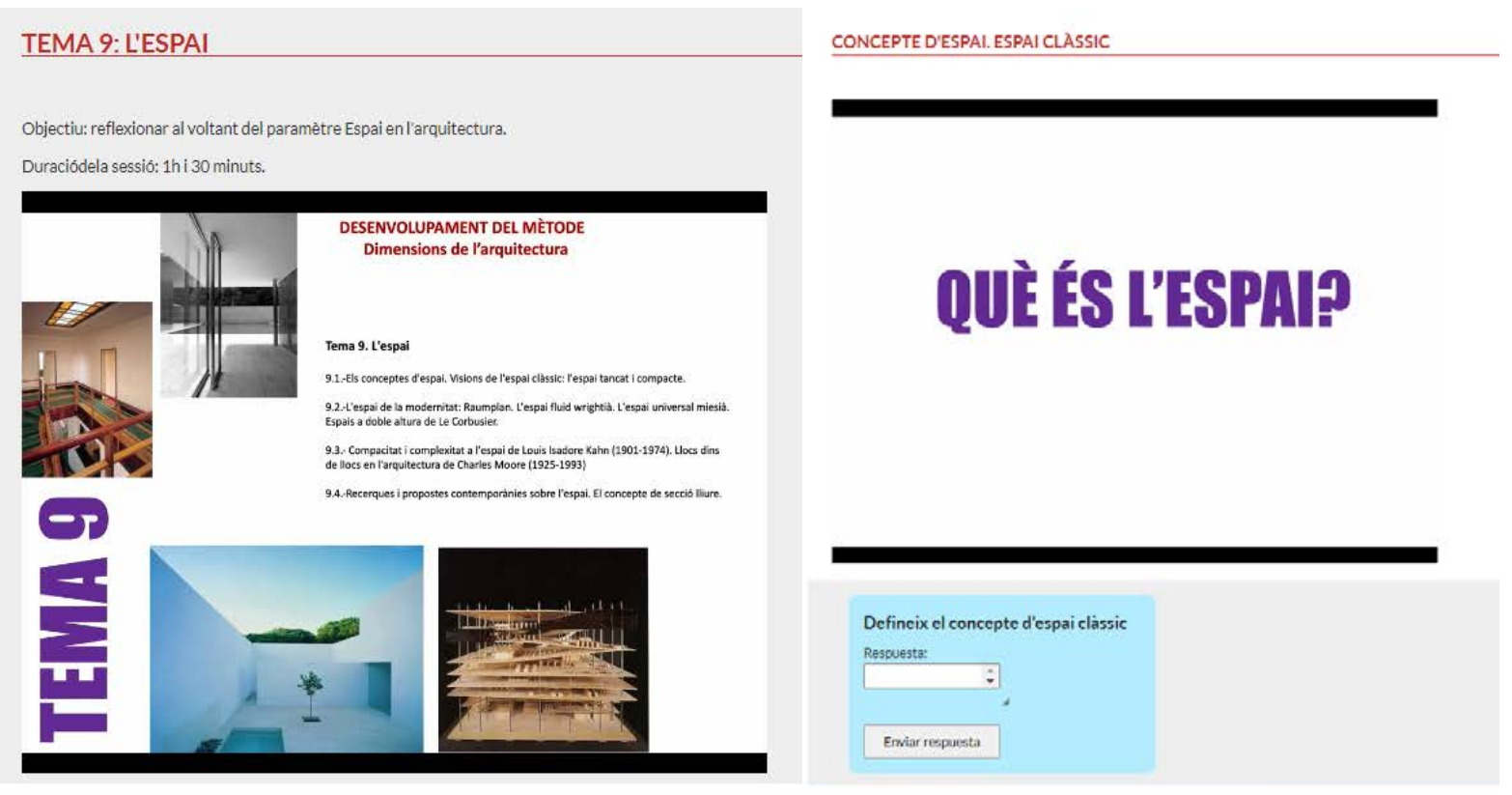

Figure. 3 Digital resource: class from Lessons, subject of architectural composition in Valencian Source: Garcia Soriano L. (2019)

\section{CONCLUSIONS}

The implementation of the ICLHE model in recent years has increased the workload for both students and teachers, careful to avoid risks due to an unsuitable command of the teaching language by both parties. To do so efforts have been made from the beginning to ensure the style was no less expressive, repetitive or clear in another language. Insistence has always been placed on linguistic variety, emphasizing the necessary reiteration and repetition of ideas and concepts. Therefore, from the beginning efforts have been made to have access to meta discourse resources and glossaries of key terms, both analogue and digital $[10,11,12]$.

Thanks to these resources students, even in the early years of the implementation of this system, have reacted positively in the surveys carried out, with no problems in comprehension (due to unsuitable pronunciation and unfamiliar vocabulary) and have assimilated content satisfactorily with results in line with those obtained by groups where the subjects have been taught in Spanish.

It should be emphasized that the lack of academic skills in the mother tongue is reflected in a lack of academic skills in the language of the ICHLE and that transition to a possible online teaching of the subjects, with extensive analogue resources, has had no negative impact on students' learning system.

\section{ACKNOWLEDGEMENTS}

This text is part of the Project for Educational Innovation and Improvement "ARQUITECTURA CRÍTICA. Desarrollo de una metodología para trabajar la competencia transversal de "Pensamiento crítico" en estudiantes de arquitectura", main researcher: C. Mileto, funded by the Institute of Education Sciences of the Universitat Politècnica de València. 


\section{REFERENCES}

[1] AA.VV. (2014) Estrategia para la internacionalización de las universidades españolas 2015-2020, Ministerio de Educación, Cultura y Deporte https://sede.educacion.gob.es/publiventa/estrategiapara-la-internacionalizacion-de-las-universidades-espanolas-2015-2020/universidad/21475 Consult January 2021)

[2] COLEMAN, J. (2010) English-medium teaching in European higher education. [Online] Journals Cambridge. http://www.journals.cambridge.org (Consult January 2021)

[3] CRYSTAL, D. (2003). English as a global language (2nd edn.). Cambridge: Cambridge University Press

[4] CRISTINI, V. (2019) Proyecto docente para concurso de plaza de profesor titular. Área de Restauración de Patrimonio. Valencia, 2019, inédito, cortesía de la autora

[5] MARSH, D. , LAITINEN,J. (2005), Medium of instruction in European higher education: Summary of research outcomes of European Network for language learning amongst undergraduates (ENLU) Task Group 4. Jyvaskyla: Uni COM, University of Jyvaskyla.

[6] MAYOR ZARAGOZA, F.,(1998) "La Universidad del siglo XXI en la perspectiva de la UNESCO", en PORTA

[7] J., LLADONOSA M. (eds), La Universidad en el cambio del siglo. Alianza Editorial, Madrid

[8] MILETO C., VEGAS F., CRISTINI V., DIODATO M. (2011), "Learning based upon projects of architectural conservation: from university to real life", en AA.VV., INTED2011, IATED, Valencia

[9] MILETO C., VEGAS F. (2011), "Teaching architectural restoration through thinking on intervention criteria", en KEALY L. MUSSO S. (cord.), Conservation / transformation, EAAE - ENHSA, Leuven, pp. 363-368

[10] SANTAMARINA V., CARABAL MaaA., VICENTE MªT.,( 2006), Conservación, restauración y Patrimonio en Internet, UPV, Valencia, recurso informático

[11] TOMASELLI, F., (2008), "Teaching Restoration Methodology: Role of Scientific Contributions in the Conservation of Architectural Heritage", en MUSSO S., DE MARCO L., Teaching Conservation /Restoration of the Architectural Heritage. Goals, Contents and Methods, EAAE, pp. 229-237

[12] WEILER, K., GUTSCHOW, N. (ed.), (2017), Authenticity in Architectural Heritage Conservation. Discourses, Opinions, Experiences in Europe, South and East Asia, Springer, Zurich 